\title{
Hunting as land use: Understanding the spatial associations among hunting, agriculture, and forestry
}

\author{
$\underline{\text { Wiebke Neumann }}^{1,2}$ Christian Levers $^{2,3,4}$ Fredrik Widemo $^{1}, \underline{\text { Navinder J. Singh }}^{1}$, Joris P. G. M. Cromsigt $^{1,5,6}$ and Tobias Kuemmerle $^{2,7}$
}

\begin{abstract}
Hunting is a widespread but often overlooked land-use activity, providing major benefits to society. Hunting takes place in most landscapes, yet it remains unclear which types of landscapes foster or dampen hunting-related services, and how hunting relates to other land uses. A better understanding of these relationships is key for sustainable land-use planning that integrates wildlife management. This is particularly urgent for Europe, where wildlife populations are increasing. Focusing on Sweden, we explored the spatial associations among hunting, agriculture, and forestry to identify archetypical combinations of these land uses. Specifically, we combined indicators on the extent and intensity of agriculture and forestry, with data on hunting bags for 63 game species using selforganizing maps, a non-parametric clustering approach. We identified 15 typical bundles of co-occurring land uses at the municipality level across Sweden. The harvest of forest grouse, bears, and moose co-occurred with forestry in northern Sweden, whereas the harvest of small game, different deer species, and wild boar co-occurred with agriculture across southern Sweden, reflecting species' biology, environmental factors, and management. Our findings also highlight the strength of associations among hunting and other land uses. Importantly, we identified large areas in central Sweden where harvest of game was below average, possibly indicating that intensity of hunting is out of balance with that of agriculture or forestry, potentially fostering conflict between wildlife and land use. Collectively, our results suggest that (1) hunting should be considered a major land use that, in Sweden, is more widespread than agriculture and forestry; (2) land-use planning must therefore integrate wildlife management; and (3) such an integration should occur in a regionalized manner that considers social-ecological context. Our approach identifies a first spatial template within which such context-specific land-use planning, aiming at aligning wildlife and diverse land uses, can take place.
\end{abstract}

Key Words: functional game groups; human-nature interactions; human-wildlife co-existence; land-use archetypes; Northern Europe; social-ecological systems; spatial clustering; ungulate overabundance; wildlife management

\section{INTRODUCTION}

Globally, hunting of wildlife is a major and geographically widespread activity (Gordon et al. 2004, Fischer et al. 2013). Hunting provides important services to society, and also controls disservices produced by wildlife (Apollonio et al. 2010). Moreover, hunting is a major recreational activity with huge economic value. There are 11.5 million hunters in the U.S. and seven million in Europe (Massei et al. 2015, U.S. Fish and Wildlife Service 2016). In the U.S., the economic value of deer hunting alone is estimated at US\$1.3 billion, and all game hunting is worth US\$26.2 billion (U.S. Fish and Wildlife Service 2016). Clearly, hunting is a widespread land use (Fischer et al. 2013), but, surprisingly, hunting has been largely ignored in wider land-use planning and policy discussions.

Usually, hunting overlaps spatially with other land uses, as game species utilize agricultural and production-forestry landscapes, and many game species are indeed favored by such landscapes (Apollonio et al. 2010, Linnell et al. 2020). For example, roe deer (Capreolus capreolus) and white-tailed deer (Odocoileus virginianus) benefit in major ways from today's fragmented landscapes (Andersen et al. 1998, Dawe et al. 2014). Likewise, wild boar (Sus scrofa) populations have been increasing massively in Europe (Massei et al. 2015). Through hunting, we obtain important ecosystems services (ESS) from wildlife, especially meat and recreation (Linnell et al. 2020). Hunting provides an estimated 32,000 tons of wild meat in Germany (Deutscher Vagdverband) and 20,000 tons in Sweden annually (Wiklund and Malmfors 2014). Many landowners today manage their land at least partly for wildlife (Oldfield et al. 2003).

Yet, wildlife is also responsible for a wide range of disservices, including crop raiding, browsing damage by ungulates that limits forestry, livestock losses due to large carnivores, and wildlifevehicle collisions (Gren et al. 2018, Linnell et al. 2020). For instance, browsing damage by moose (Alces alces) in Sweden is estimated to be at least $€ 50$ million annually, crop damage by wild boar in France exceeded $€ 21$ million in 2004/2005 alone (Apollonio et al. 2010), and wildlife-vehicle collisions incur high economic costs, e.g., $€ 100$ million in 2006 in France (Apollonio et al. 2010, Gren et al. 2018). Whereas anthropogenic activities and habitat modifications often positively affect growth of game populations, in many regions, natural predators no longer control these populations, making hunting a key mechanism for controlling the disservices that these game populations produce (Fischer et al. 2013, Linnell et al. 2020). Considerable research

\footnotetext{
${ }^{1}$ Department of Wildlife, Fish and Environmental Studies, Swedish University of Agricultural Science, Sweden, ${ }^{2}$ Department of Geography, Humboldt-University Berlin, Germany, ${ }^{3}$ Institute for Resources, Environment and Sustainability, University of British Columbia, 2202 Main Mall, Vancouver, BC, V6T 1Z4, Canada, ${ }^{4}$ Department of Environmental Geography, Institute for Environmental Studies (IVM), Vrije Universiteit Amsterdam, De Boelelaan 1087, $1081 \mathrm{HV}$, Amsterdam, The Netherlands, ${ }^{5}$ Copernicus Institute of Sustainable Development, Utrecht University, Princetonlaan 8a, 3584 CB Utrecht, ${ }^{6}$ Centre for African Conservation Ecology, Department of Zoology, Nelson Mandela University, Port Elizabeth, South Africa, ${ }^{7}$ Integrative Research Institute for Transformation in Human-Environment Systems (IRI THESys), Humboldt-University Berlin, Germany
} 
has gone into how hunting can mitigate conflicts with other land uses (Weisberg and Bugmann 2003, Harrison et al. 2018), yet our understanding of which landscapes foster or dampen huntingrelated services and disservices remains limited.

New approaches to identifying typical combinations of land uses and the bundles of (dis)services they produce also have considerable potential to provide novel insights into spatial associations of hunting and other land uses, thereby allowing smarter landscape planning (Karrasch et al. 2019, Sietz et al. 2019). For example, spatial clustering can map archetypical landscapes according to the extent and intensity of major land uses (Václavik et al. 2013, Levers et al. 2018), providing useful spatial templates for assessing landscape multi-functionality (Stürck and Verburg 2017). Likewise, archetype approaches can identify typical bundles of co-occurring services, which can reveal hotspots and coldspots of service provisioning, and be useful to explore trade-offs and synergies between services (RaudseppHearne et al. 2010, Turner et al. 2014, Cord et al. 2017). Such bundles can help to recognize areas prone to conflicts among stakeholders, and are thus starting points for implementing policies to mitigate such conflicts (Frei et al. 2018).

Yet, we know of only a handful of studies formally assessing the spatial relationships between ESS provided by hunting, i.e., considering deer or ungulates, and by other land uses. For example, previous studies have emphasized how deer hunting is spatially associated with forestry and recreation values in space (see, e.g., studies in Canada; Raudsepp-Hearne et al. 2010) or in Denmark (Turner et al. 2014). Depending on the environmental context, however, hunting can also be relatively disconnected from other land uses in space, e.g., ungulate hunting in the French Alps (Crouzat et al. 2015, Spake et al. 2017). Importantly, by focusing on deer hunting, i.e., forest-dwelling species, and not considering other game species, previous studies may have underestimated the spatial distribution of hunting as well as its association with land uses beyond forestry, e.g., low connection between agriculture and moose hunt (Queiroz et al. 2015, Meacham et al. 2016). Hunting provides provisioning, e.g., game meat, cultural services, e.g., hunting tradition, recreation, and may modify regulating services, e.g., through population control of predators or browsers (Fischer et al. 2013), but is generally considered to provide cultural services. This may affect the interpretation of the spatial interaction observed with other services, particularly with the provisioning services produced by other land uses (Raudsepp-Hearne et al. 2010, Turner et al. 2014, Queiroz et al. 2015, Meacham et al. 2016, Spake et al. 2017). Previous mapping of social-ecological systems related to ungulate management emphasized the regional diversity in hunting and other land uses (Dressel et al. 2018), underscoring the need for integrating hunting to land-use management to ensure sustainable multi-functionality. Although all these studies highlight the potential value of the archetype approaches to assess spatial patterns in hunting as related to services and disservices, we still lack studies that consider hunting of a diverse range of game species, i.e., beyond ungulates, and how the hunting of these diverse game species is spatially associated with other land uses.

Identifying archetypical combinations of land uses, including hunting, would have direct management implications. First, despite clear links between hunting, agriculture, and forestry, spatial planning and policy making in these sectors still largely occurs separately within sectors (Beguin et al. 2016, Albert et al. 2020). This frequently leads to unintended outcomes, such as when bioenergy policies lead to more favorable wildlife habitat, which in turn increases crop damage (Apollonio et al. 2010, Massei et al. 2015). Cross-sectoral (i.e., wildlife management, agriculture, and forestry) planning and management recognizing relationships between land uses and different services is therefore needed (Fischer et al. 2013, Prager et al. 2018, Linnell et al. 2020). Second, environmental conditions, extent and intensity of land uses, and the archetypes they produce all vary considerably in space. This variability translates into an urgent need for context specificity in land-use planning (Simoncini et al. 2019, SjolanderLindqvis and Sandström 2019). Unfortunately, spatial templates for such regionalized planning are often missing (Sayer et al. 2013). In particular, regions will often not overlap directly with administrative boundaries in which management and planning usually takes place. Identifying appropriate spatial templates for cross-sectorial planning is therefore important.

Europe is particularly relevant in this context, because many game species, such as ungulates, large carnivores, and geese, have expanded both their populations and distributions in recent years (Chapron et al. 2014, Fox and Madsen 2017, Linnell et al. 2020). As a result, interactions between wildlife, agriculture, and forestry have intensified (Linnell et al. 2020). Hunting remains an important activity in many European regions (Apollonio et al. 2010), but its intensity and spatial footprint is changing as well. For instance, even though the economic value of hunting increases (Boman et al. 2011), hunter numbers are stable or declining (Apollonio et al.2010), and outmigration now characterizes many rural areas in Europe and elsewhere (Navarro and Pereira 2012). Finally, a variety of land systems characterizes Europe, including highly intensified as well as multi-functional landscapes with high cultural heritage and conservation value (Tieskens et al. 2017, Levers et al. 2018). Europe's human-dominated landscapes host a variety of game species, birds, as well as mammals. Although considerable effort has gone into identifying and mapping typical land systems in Europe (Levers et al. 2018, Schulp et al. 2019), how they are changing (Kuemmerle et al. 2016), and how they relate to ecosystem services (Van der Zanden et al. 2016, Holting et al. 2019), hunting has been largely ignored in this context.

Here, we focus on Sweden, where forestry and agriculture are major land uses, and where hunting is widespread: about $3 \%$ of the adult populations are hunters, about $4 \%$ own forest, and $2 \%$ are involved in agriculture (Apollonio et al. 2010, Swedish Forest Agency 2018, Swedish Board of Agriculture 2018). Since the 1960s, forestry, agriculture, and hunting have gone through major transformations in Sweden, resulting in intensified forestry and agriculture, yet also in an increased emphasis on multifunctionality and conservation goals (Antonson and Jansson 2011). For example, ungulate management, particularly of moose, shifted in major ways towards ecosystem-based management (Bjärstig et al. 2014). The economic value of hunting, especially of ungulates, is large and growing; in Sweden it totals US\$489 million (Widemo et al. 2019). However, the extent and intensity of hunting, agriculture, and forestry varies considerably throughout Sweden, and the perception of wildlife management in these multi-use landscapes depends on the social-ecological context (Dressel et al. 2018). While hunting correlates positively 
with provisioning services (Queiroz et al. 2015), higher socialecological diversity, e.g., co-occurrence of several ungulate species, high levels of browsing damages, and landowner diversity, may also come with higher levels of disagreement on ungulate management goals among land user actors (Dressel et al. 2018). Given the growing ungulate populations and the conflict potential this represents for agriculture and forestry (Apollonio et al. 2010), a more regionalized and cross-sectoral planning that integrates hunting, agriculture, and forestry as land uses is urgently needed (Angelstam et al. 2017).

Our overarching goal was to understand how hunting (here defined as harvest of both all game species and of ungulates specifically), agriculture, and forestry are spatially associated. We gathered nine indicators on the extent and intensity of agriculture and forestry, and hunting bags for 63 game species. Hunting bags here represent the number of animals harvested in a given hunting unit (Jaktvårdskrets; SAHWM 2018; https://www.algdata.se/). We evaluated two sets of hunting indicators. One set comprised all 63 game species in eight functional groups, e.g., forest grouse, agriculture birds, waterfowl, hares, meso-predators, aquatic mammals, bears, and ungulates. The other set consisted of the five most important ungulate species, to account for their dominance in game-meat supply (Widemo et al. 2019) and the fact that they frequently occur in conflict with other land uses (Linnell et al. 2020): moose, roe deer, red deer (Cervus elaphus), fallow deer (Dama dama), and wild boar. We applied spatial clustering, based on self-organized maps (SOMs) to identify typical bundles of land uses that co-occur at municipality level. Using Sweden as a case, we addressed the following research questions: (1) What are typical bundles of co-occurring hunting, agriculture, and forestry? (2) What is the spatial pattern of these bundles, and how do they differ for different game species groups?

\section{MATERIAL AND METHODS}

\section{Study area}

Sweden extends across 14 degrees of latitude in northern Europe. The country is sparsely populated (10 million inhabitants at 25 persons $/ \mathrm{km}^{2}$ ) and most of the population lives in the south (Statistics Sweden 2019). Sweden has 290 municipalities with each having a strategical overview plan that defines the long-term planning regarding municipalities' development and use of land locally and regionally. As such, municipalities are relevant players within the planning of multiple land-use interests. The country encompasses four global ecological zones with a distinct change in vegetation around latitude $60^{\circ} \mathrm{N}$ (Limes norrlandicus, Fig. 1). Whereas boreal forest dominates north of this line, mosaic landscapes composed of coniferous forest, deciduous forest, and agriculture characterize the south. In addition, mountainous and alpine vegetation dominate in the Scandes, along the border with Norway. Topography varies from flat areas in the south to alpine areas in the northwest. Elevations range from zero to about 2100 meters above sea level.

Corresponding to the major vegetation zones, game species, agriculture, and forestry are distributed unevenly across the country. Forestry dominates in the north, whereas agriculture occurs mainly in the south. Hunting has a long tradition in Sweden and occurs on most land, yet with focus on different game species. Historically, hunting of ungulates was an important land use and, as elsewhere in Europe, replaced predation as the main mortality cause (Apollonio et al. 2010). Among the five most important large ungulate species, moose and roe deer occur throughout mainland Sweden, whereas wild boar, red deer, and fallow deer occur mainly in the south. Sweden thus provides an excellent study system to evaluate spatial associations among hunting, agriculture, and forestry along strong environmental and climatic gradients.

Fig. 1. Distribution of province borders (brown lines), municipality borders (grey lines), ecological zones, and Limes Norrlandicus (dotted black line) in Sweden (black line).

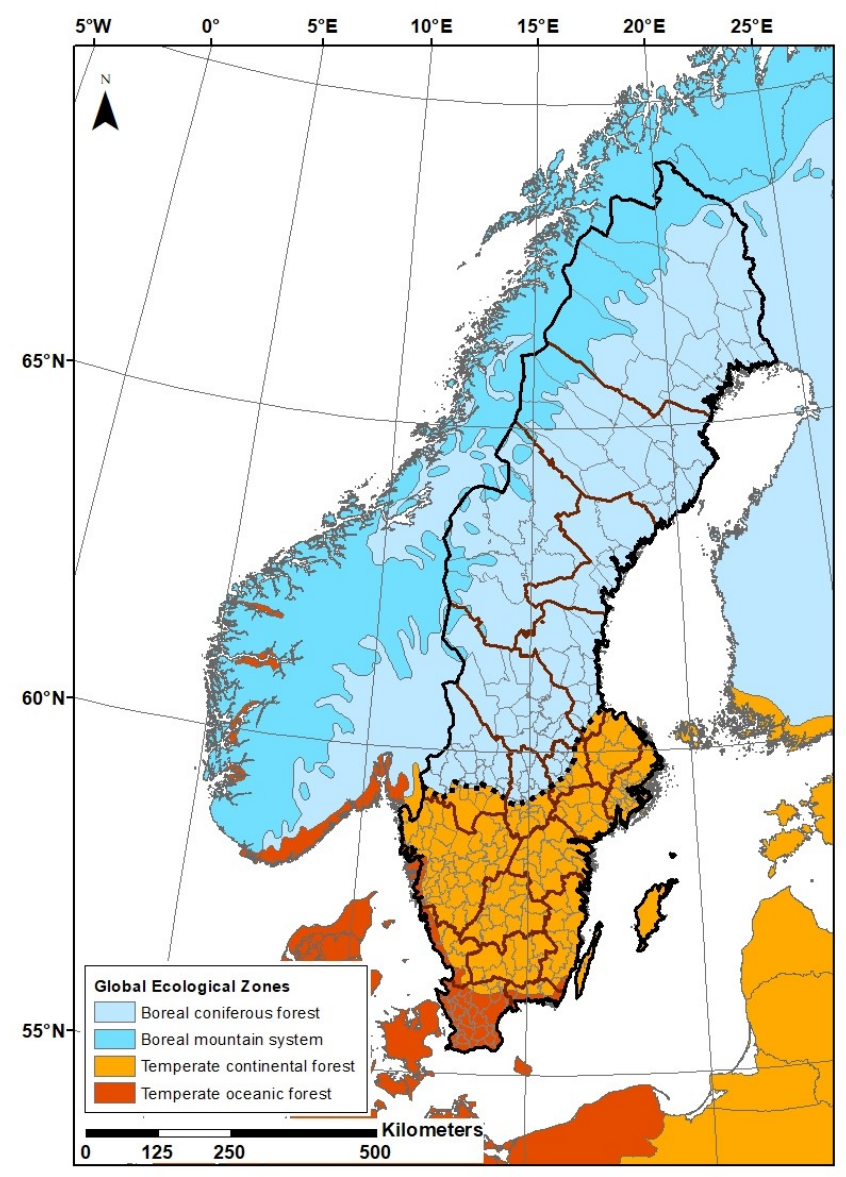

\section{Input data and pre-processing}

We carried out our analyses at the municipality level, the most detailed level for which most official statistics were available. We derived 22 spatial indicators to address the three major land-use sectors: agriculture, forestry, and hunting (Table A1.1) and gathered data for the period 2008-2016. We averaged all indicators over the entire study period to account for spurious signals emerging from analyzing snapshots in time for some data in some municipalities (Cord et al. 2017; Table 1). We excluded three urban municipalities (Stockholm, Malmö, and Gothenburg) because their urban profile excluded our target land uses.

For hunting, we analyzed: (1) hunting bags (number harvested) of all game summarized in eight functional groups (forest grouse, 
Table 1. List of parameters on the extent and intensity of agriculture, forestry, and hunting used as indicators to identify bundles of land use across Sweden and the calculated estimates (mean \pm standard deviation (SD), minimum and maximum values) for each parameter.

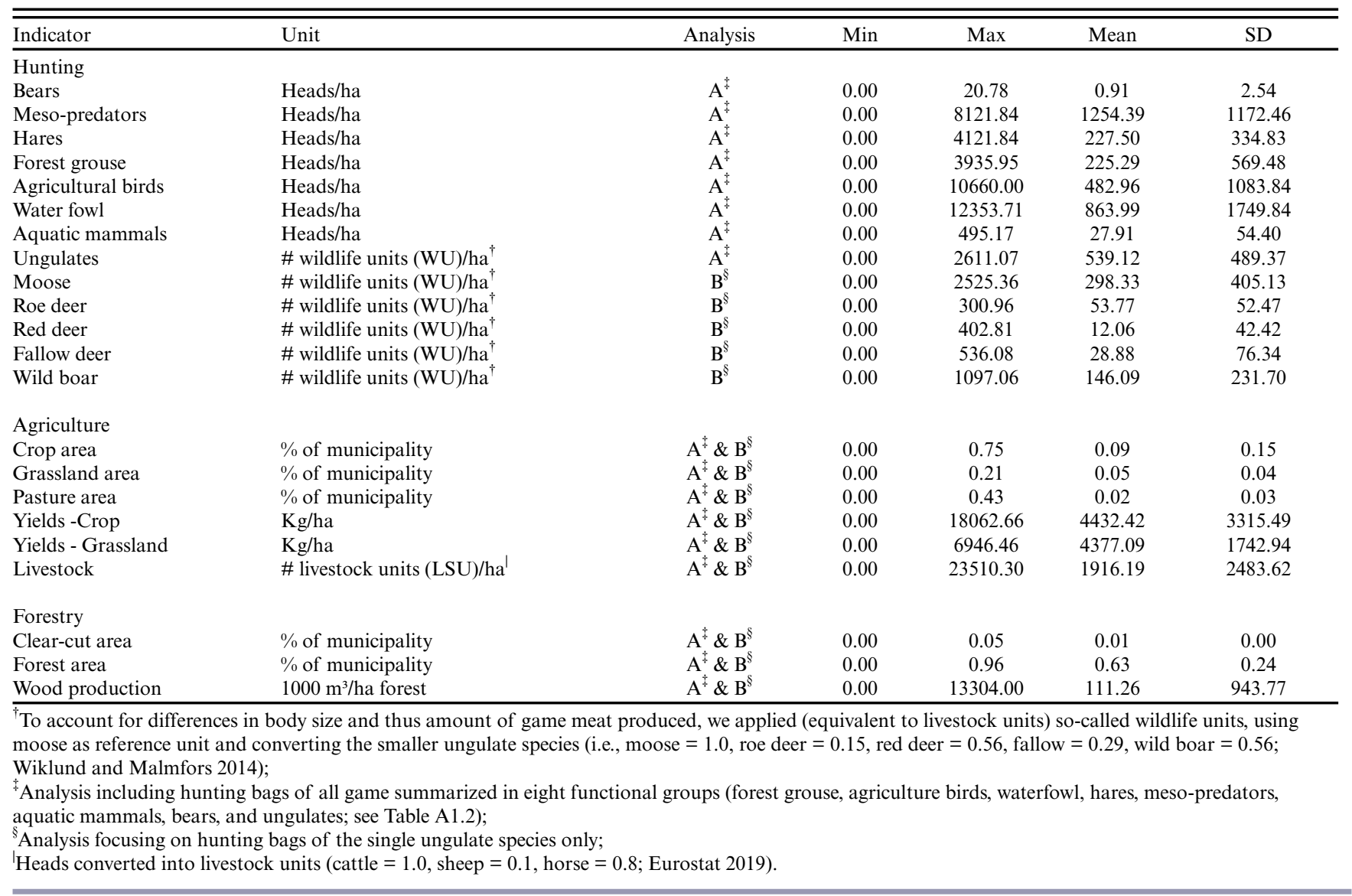

agriculture birds, waterfowl, hares, meso-predators, aquatic mammals, bears, and ungulates); (2) hunting bags of the single ungulate species (Table A1.2). Borders of hunting units and municipalities do not always overlap, and we therefore calculated area-weighted estimates per municipality, using the area of hunting units as weights. Next, we expressed the harvested animals per municipality area (number of heads/ha). To account for differences in body size among ungulates, we calculated wildlife units (equivalent to livestock units), using moose as a reference unit: i.e., moose $=1.0$, roe deer $=0.15$ ( 6.6 roe deer equal 1 moose $)$, red deer $=0.56(1.8$ red deer equal 1 moose $)$, fallow $=$ 0.29 (3.4 fallow deer equal 1 moose), wild boar $=0.56$ ( 1.8 wild boar equal 1 moose; Wiklund and Malmfors 2014). Because other game species, e.g., meso-predators and birds, are hunted for other reasons than meat, we decided to use bag counts for these species.

For agriculture, we collected data on the extent of croplands and pastures, as well as their productivity (yields and livestock units). We summarized data on cropland and pasture extent (ha) and livestock heads (cattle, sheep, and horses) on the municipality level (Swedish Board of Agriculture 2018). We converted livestock heads into livestock units using official conversion rates (cattle = 1.0, sheep $=0.1$, horse $=0.8 ;$ Eurostat 2019). Crop yield data $(\mathrm{kg} /$ ha) for different crop types was available at the county level (Statistics Sweden 2018). To match the resolution of the other data, we used municipality-level crop extents for each crop type separately to calculate crop yields at the municipality level of a given crop type (Table A1.3). We first multiplied the extent per crop type within a municipality with its yield $(\mathrm{kg} / \mathrm{ha})$ in the corresponding county (assuming within-county yield homogeneity) to obtain municipality-level crop production per crop type $(\mathrm{kg})$. Because we were interested in an overall measure of the crop produced per municipality, we then calculated total crop production $(\mathrm{kg})$ over all crop types for each municipality and divided this by the total extent (ha) of all crop types to obtain municipality-level yields $(\mathrm{kg} / \mathrm{ha})$ for all crops combined (hereafter: crops). Data on pasture at municipality-level was available in two ways: as extent (ha) and production ( $\mathrm{kg} / \mathrm{ha}$ ) of fodder, e.g., silage and hay (hereafter: grassland), and as the extent of land utilized by livestock for foraging (hereafter: pasture).

For forestry, we collected data on the extent (forest cover) and intensity of forestry (wood production). We summarized the extent (ha) of forest (sum of productive and non-productive forest) and clear-cuts (ha) on municipality level (Swedish Forest Agency 2017, Statistics Sweden 2018). However, the resolution available for gross wood production $\left(1000 \mathrm{~m}^{3} / \mathrm{ha}\right.$ forest) only 
Fig. 2. Sum of harvested game in eight functional groups per hectare (ha) within a given municipality in Sweden, 20082016. Municipalities with zero animals harvested are in white. $\mathrm{WU}=$ wildlife units.
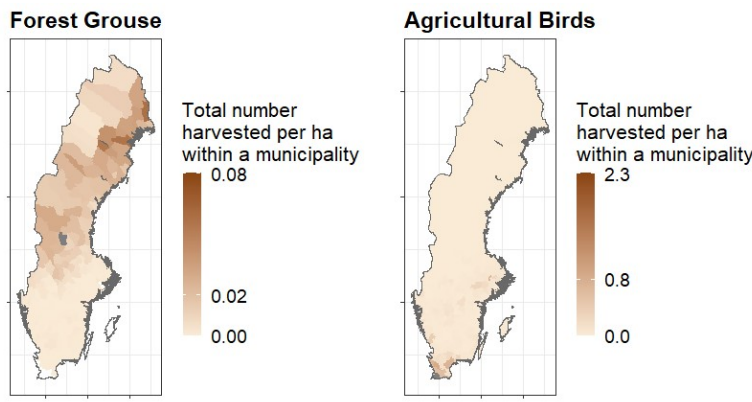

Meso-Predators

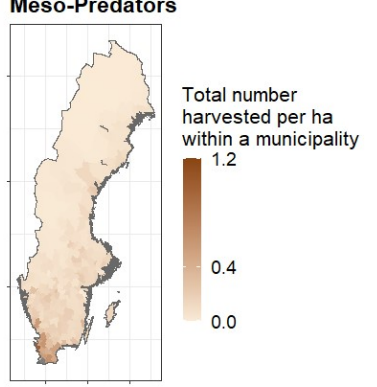

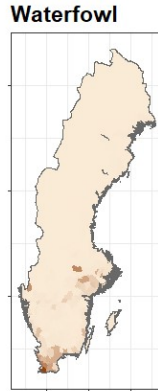

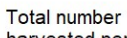
harvested per ha within a municipality 2.2

Aquatic Mammals

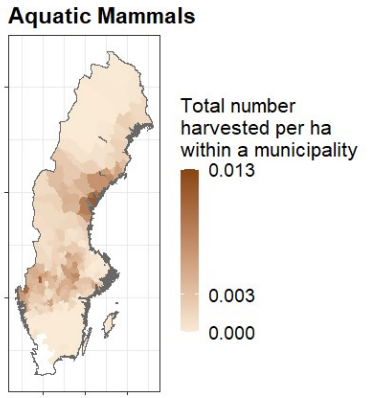

Bears

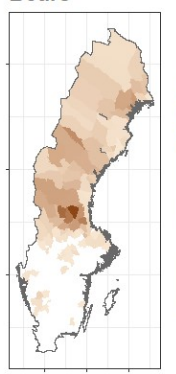

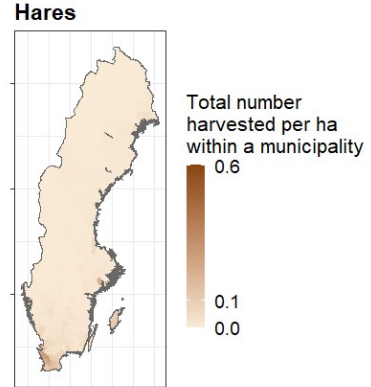

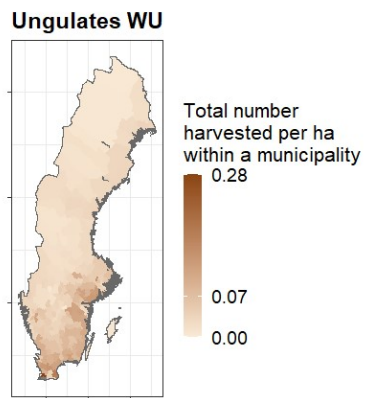

allowed a summary at the county level (Swedish Forest Agency 2017).

\section{Spatial clustering}

We used SOMs to map typical bundles of hunting, agriculture, and forestry in Sweden. SOMs are an automated, non-parametric clustering technique relying on an unsupervised, competitive learning algorithm (Kohonen 2001). SOMs group observations based on their similarity in feature space, including geographic location, thereby preserving data topology. Specifically, SOMs seek to minimize within-cluster variability while maximizing contrast across clusters. These features render SOMs well-suited to analyze and visualize high-dimensional data and its complexity (Ripley 1996). Before running the clustering, we scaled all indicators to zero average and unit-standard deviation to allow for comparability across indicators. Like other clustering algorithms, SOMs require a priori definition of the number of clusters, to which observations are assigned. We performed extensive pre-tests to identify the appropriate cluster number (ranging from one to 25). We determined the optimal cluster number using the natural breakpoint in the mean Euclidean distance of the samples to their cluster centroid and the DaviesBouldin cluster index, which relates intra- to inter-cluster variability (Levers et al. 2018).

Once optimal cluster numbers were identified, we implemented two alternative cluster analyses (A and B, Table 1). First, cluster analysis A used all indicators for agriculture (cropping and pastures) and forestry, and indicators for all game species, summarized as eight game functional groups (hereafter: wildlife bundles). Second, cluster analysis B used the same indicators for agriculture and forestry and combined them with indicators for the five ungulate species (hereafter: ungulate bundles). We used the kohonen (Wehrens and Buydens 2007) and clusterSim (Walesiak and Dudek 2014) packages in R to perform all analyses (R Foundation 2019).

\section{RESULTS}

There were 10,683,439 animals harvested during our nine-year study period, of which ungulates alone contributed 2,680,248 animals. Hunting occurred throughout Sweden, but harvest intensities of functional groups and ungulate species varied across and along latitudinal gradients (Figs. 2 and 3). We found similar harvest patterns for certain groups and species: harvest of forest grouse and bears was dominantly or exclusively located in northern Sweden, whereas agriculture birds, waterfowl, and smaller ungulate species (roe deer, wild boar, fallow deer, and red deer) were mostly harvested in the south. Harvest intensities of ungulates were higher in southern Sweden and along the east coast, even though more animals were shot in northern municipalities, e.g., moose (Fig. 3; Figs. A1.1, A1.2).

Our cluster analysis A based on data from eight functional game groups, agriculture, and forestry indicators yielded 15 typical wildlife bundles (Fig. 4-I; Fig. A1.3A). To highlight the level of interactions between game harvesting and other land uses, we grouped these bundles along an interaction-gradient, resulting in six categories, from weak to strong interactions (Fig. 4-II). Strong interactions, i.e., higher harvest in areas of higher land-use intensity of agriculture and forestry (green colors), characterized the southernmost parts of Sweden as well as the coastal areas in northern Sweden. Bundles with weaker interactions, i.e., average estimates for most parameters (purple colors), characterized most of central southern Sweden, whereas bundles with moderately intense relationships, i.e., above average, but not very high (blue colors), characterized northern Sweden. A below-average bundle 
Fig. 3. Sum of harvested moose (Alces alces), roe deer (Capreolus capreolus), red deer (Cervus elaphus), fallow deer (Dama dama), and wild boar (Sus scrofa; wildlife units) per hectare (ha) within a given municipality in Sweden, 2008-2016. Municipalities with zero animals harvested are in white. Wildlife units (WU) using moose as reference unit (i.e., moose $=1.0$, roe deer $=0.15$, red deer $=$ 0.56 , fallow $=0.29$, wild boar $=0.56$; Wiklund and Malmfors 2014).

Moose

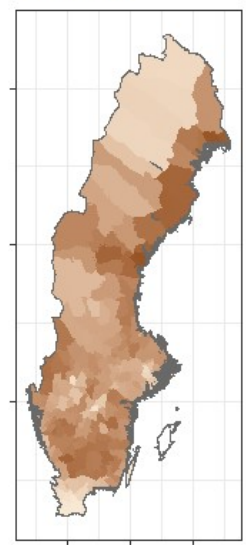

\section{Fallow deer WU}

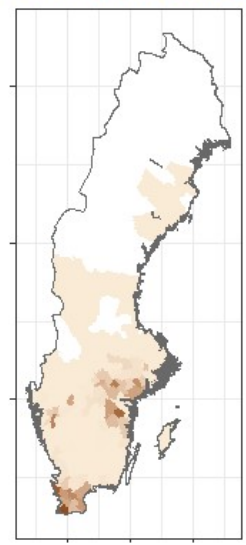

Total number harvested per ha within a municipality 0.04

0.02

0.00

Roe deer WU

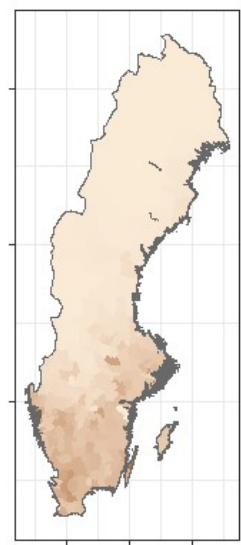

Total number harvested per ha within a municipality 0.07

0.02

0.00
Wild boar WU

Total number harvested per ha within a municipality 0.04

0.01

0.00

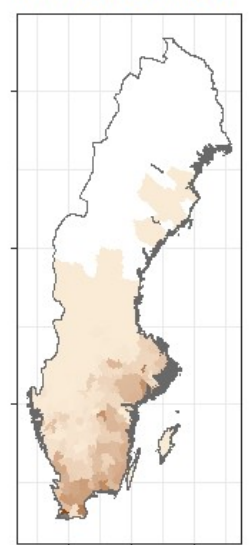

Total number

harvested per ha within a municipality

0.17

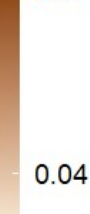

0.00
Red deer WU

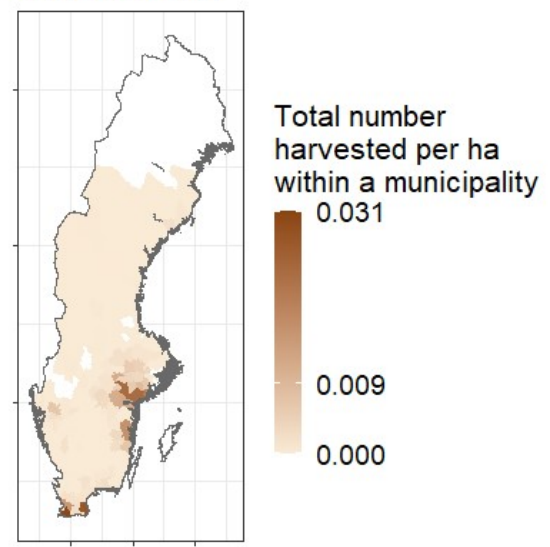

for most parameters studied defined the northernmost mountainous municipalities (C7, Fig. 4-I). Few bundles were clearly dominated by only one of the land uses, i.e., grey or yellow color.

Five wildlife bundles occurred spatially concentrated and together covered about $75 \%$ of the country: two bundles in northern Sweden (C7 and C13, Fig. 4-I), two in the interior of southern Sweden (C11 and C12, Fig. 4-I), and one following the Limes norrlandicus (C10, Fig. 4-I). A noticeable spatial separation along this vegetation-climatic border occurred with fewer bundles in the northern boreal zone compared to the southern boreal and nemoral zone. Difference in average municipality size resulted in bundles covering much larger areas in the north. For some functional game groups, e.g., hares, and particularly ungulates, hunting co-occurred nationwide with either agriculture or forestry (C2, C4, C11, C14, and C15, Fig. 4-I), showing varying degrees of relations between game harvest patterns and agriculture and forestry intensities. Crop and grassland intensity were positively associated with harvest of waterfowl, agricultural birds, hares, ungulates, and meso-predators (C2, C4, and C14, Fig. 4-I), particularly in the south. Harvest intensities of aquatic mammals, bears, and forest grouse linked positively to forest occurrence, but also to forestry intensity $(\mathrm{C} 1, \mathrm{C} 3, \mathrm{C} 4, \mathrm{C10}, \mathrm{C} 13$, and C15, Fig. 4-I). Two bundles (C10 and C12, Fig. 4-I) described a clearly distinct region of above-average forestry or agriculture intensities, but below-average ungulate harvest along the Limes norrlandicus. In contrast to these clearly large-delineated bundles, the region near Stockholm contained a diverse group of bundles with some bundles highlighting the co-occurrence of harvest of diverse functional game groups and agriculture or forestry (C11 and C14, Fig. 4-I), whereas others representing single land uses, e.g., harvest and agriculture (C6 and C12, Fig. 4-I).

Our cluster analysis B based on indicators of ungulate species resulted in 15 ungulate bundles (Fig. 5-I; Fig. A1.3B). These show similar patterns along the interaction-gradient as in case of the wildlife bundles with moderately intense interactions between 
Fig. 4. Figure I (left) shows cluster analysis A: wildlife bundles defined by the quantification of indicators that discriminate each bundle. Figure II (right) shows their spatial arrangement as given by automated clustering of self-organized maps (SOMs), based on empirical data about hunting (summarized in eight functional game groups), forestry, and agriculture in Sweden, $2008-2016$. Province borders in brown, municipality borders in grey, and Limes Norrlandicus a dotted black line. LU $=$ land use.

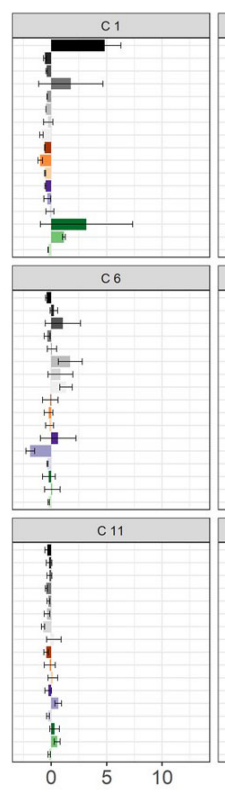

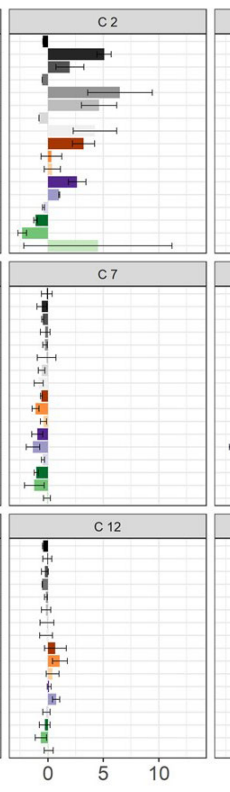

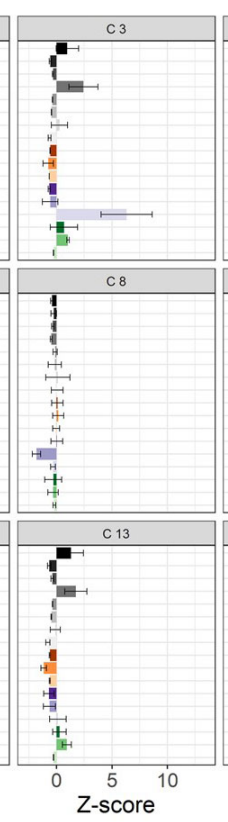

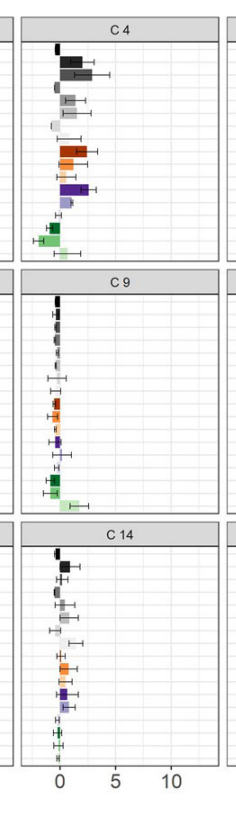

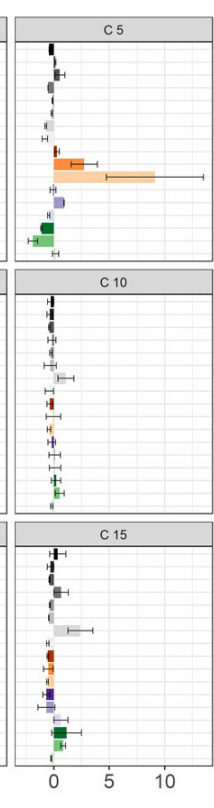

II

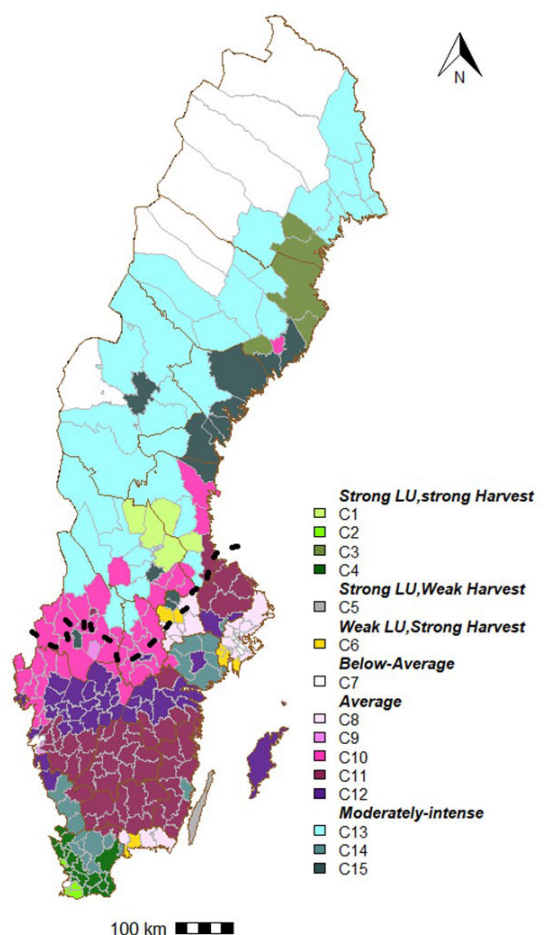

ungulate harvest and forestry or agriculture describing most of northern Sweden and the interior southern Sweden (blue colors, Fig. 5-II). Along the Limes norrlandicus, bundles of averagerelationships (purple colors) bordered bundles of high gameharvest intensities, but low agriculture and forestry intensities (yellow colors) and bundles of high agriculture and forestry intensities, but low harvest intensities (red colors). Strong relationships between ungulate harvest and agriculture (green colors) characterized the southernmost of Sweden.

Harvest of each ungulate species showed distinct, but different, patterns in relation to intensity and distribution of agriculture and forestry. As for the wildlife bundles, the Limes norrlandicus represented a distinct spatial separation. Five bundles characterized northern Sweden (C5, C6, C9, C14, and C15, Fig. 5-I) that covered large homogeneous regions. For example, along the coastline, moose harvest co-occurred closely with forest and forestry, but also with livestock (C6 and C15, Fig. 5-I). Two major bundles characterized the northern interior and the mountain chain and emphasized the association between forestry and below-average ungulate harvest values (C14, Fig. 5-I) as well as below-average values for most parameters in the mountains $(\mathrm{C} 9$, Fig. 5-I). In contrast, in southern Sweden, bundle distribution was more diverse and heterogeneous, containing 10 out of 15 ungulate bundles. Average and moderately intense associations between ungulate harvest intensities and the other land uses described the region around and south of the Limes norrlandicus (C10, C11, and C13, Fig. 5-I). The co-occurrence of forest and grassland with harvest of moose and roe deer characterized the southern interior (C12, Fig. 5-I). Pasture and grassland, and to some degree cropland, co-occurred and correlated positively with harvest of all smaller ungulates and generated strong interactions in the southernmost of Sweden and on Öland, e.g., high intensities of agriculture and harvest (C1-C4, Fig. 5-I). A patchwork of several bundles characterized the east coast in south-central Sweden, where higher values of agriculture, e.g., grassland and crops, as well as forest and forestry co-occurred to varying degrees with game harvest, particularly roe deer and wild boar, and also red deer and fallow deer (C7, C8 and C10-C12, Fig. 5-I).

\section{DISCUSSION}

Understanding key spatial associations of land uses, and the bundles of services these associations produce, is important to manage trade-offs between different land uses. Hunting is an often overlooked land-use activity in this context. Using Sweden as a case, we carried out the first systematic assessment of the spatial association of hunting on different functional game groups, and the extent and intensity of agriculture and forestry. Four main findings derive from our work. First, we found that hunting is a very widespread activity that occurs ubiquitously throughout Sweden, covering substantially more area than other major land uses, including forestry ( $58 \%$ of Sweden is used for forestry; Statistics Sweden 2015) and agriculture (8\%; Statistics Sweden 2015). Given the large area footprint of hunting, we therefore suggest that hunting should be considered a major land use by 
Fig. 5. Figure I (left) shows cluster analysis B: ungulate bundles defined by the quantification of indicators that discriminate each bundle. Figure II (right) shows their spatial arrangement as given by automated clustering of self-organized maps (SOMs), based on empirical data about hunting of five ungulate species, forestry, and agriculture in Sweden, 2008-2016. Province borders in brown, municipality borders in grey, and Limes Norrlandicus a dotted black line. LU $=$ land use.

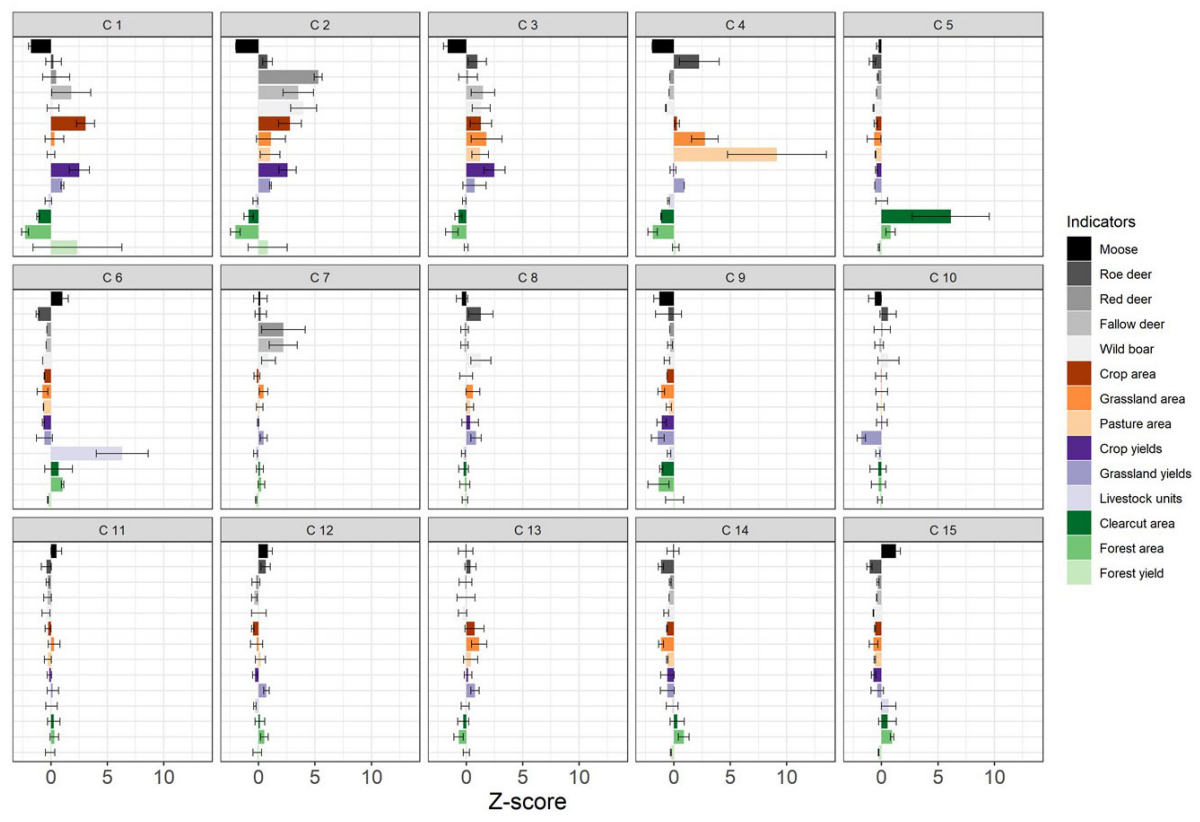

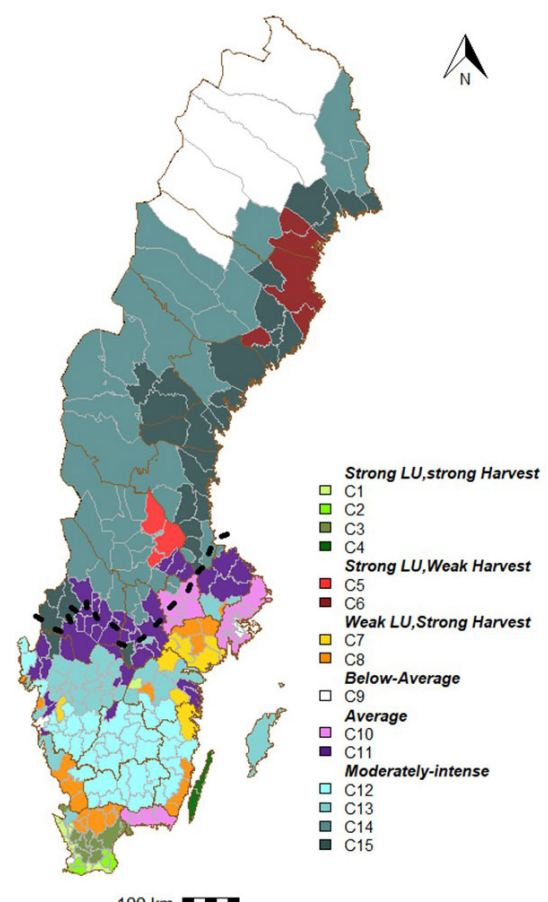

itself in land-use planning and policy making. Second, we find strong spatial associations between hunting, agriculture, and forestry, with bundles clearly related to specific environmental conditions, socioeconomic and institutional factors, and legacy effects. Third, although some bundles were geographically clustered, others occurred highly dispersed, extending across jurisdictions. This emphasizes the need for context-specific planning and policy making that transcends traditional administrative boundaries. Finally, our bundles pointed to areas where harvest rates were below-average in relation to intensities of agriculture or forestry, which may indicate areas where services produced by hunting being small relative to services produced by the other land uses.

The widespread harvest of game across all types of landscapes that we found, i.e., from the temperate forests to the boreal forests and alpine areas, suggests hunting should be considered a main land use in policy making and planning. Many indicators support such a view. First, game meat provides a sizeable economic value (Widemo et al. 2019). Second, game meat is increasingly seen as a climate-smart alternative to conventional meat (Schiermeier 2019). In Europe, where countries allow game-meat trade (Ljung et al. 2012), this could increase the economic value of hunting substantially beyond its recreational value (Gren et al. 2018). Third, hunting rights can become a key factor driving land prices (Mensah and Elofsson 2017). Clearly, of the different game species, ungulate harvest is most relevant in Sweden, particularly in the south, and dominated four of 15 bundles in our study: southernmost (C2 and C4, Fig. 4-I) and at the southeastern coast (C6 and C14, Fig. 4-I). Wildlife harvest provides provisioning, e. g., ungulate meat, and cultural services, e.g., harvest of forest grouse, waterfowl, aquatic mammals, and deer, and can alter regulating services as well, e.g., population control of mesopredators, bears, and ungulates (Fischer et al. 2013). Nevertheless, many current studies still mostly consider its cultural service (Raudsepp-Hearne et al. 2010, Turner et al. 2014, Queiroz et al. 2015, Spake et al. 2017). Based on our points above, we argue that this limited view is no longer justified. Moreover, as we show in our study, there are major spatial relationships to other land uses, such as agriculture and forestry, which may provide forage to wildlife, but may also suffer from the disservices this wildlife delivers. The bundles of hunting, agriculture, and forestry as land uses that we identified do not closely match with traditional management units (in Sweden typically provinces, the brown lines in Figs. 4-II and 5-II), translating into a need for a contextualized policy making and planning that transcend traditional policy boundaries.

We found clear spatial associations among hunting, agriculture, and forestry. More specifically, agriculture was positively associated with harvest of waterfowl, agricultural birds, hares, (smaller) ungulates, and meso-predators in southern Sweden, whereas harvest of forest grouse, bears, moose, and aquatic mammals co-occurred generally with forest and forestry in northern Sweden. Social, cultural, ecological, and economic aspects shape hunting locally (Fischer et al. 2013), modifying the 
spatial structure of hunting across landscapes, e.g., harvest of aquatic mammals or bears. For Sweden, environmental and social factors, e.g., wildlife distribution, hunting traditions, and landscape features, appear to jointly shape the spatial heterogeneity we found. Social-ecological perspectives help clarify the variation among services produced by wildlife and their relation to other land uses (Meacham et al. 2016, Dressel et al. 2018). For example, diversity in both environmental and ownership type may affect the level of agreement among land uses (Dressel et al. 2018). Interestingly, our analyses discriminated the same service-poor bundle in southern Sweden (single-land-use agriculture; C12, Fig. 4) as identified at the European level (Levers et al. 2018), highlighting the strong separation of service-poor bundles and service-rich bundles (multi-functional landscapes) across different scales. Yet, it can be challenging to understand the exact social-ecological drivers for the services produced as relationships might be complex (Meacham et al. 2016). For example, land-use intensifications may come at a cost of lost multi-functionality (Holting et al. 2019). This was partly supported by our findings: moose harvest rates were lower in bundles with high forestry intensities, e.g., northern Sweden for moose (C5 and C9, Fig. 5). Yet, we also found several bundles where high-intensive agriculture co-occurred with high harvest rates for diverse wildlife groups, e.g., southern Sweden and at the coast in northern Sweden (C1-C4, Fig. 4). Institutional boundaries are clearly visible in our bundles as we found different land-use patterns among neighboring municipalities, indicating different local decision making. In Sweden, municipal plans define landscape planning and seek to mediate among conflicting land-use interests (Bjärstig et al. 2018, Svensson et al. 2020), explaining the strong imprint of municipalities. Finally, land-use legacies shape landscapes and ecosystem service bundles (Renard et al. 2015), because they influence the capacity to provide services and therefore should be considered in land-use decision making (Requena-Mullor et al. 2018). This should also be the case for wildlife distributions and wildlife-related services, e.g., long-term effects of forest clear-cutting (Apollonio et al. 2010).

We found marked variability in spatial clustering with some clusters being concentrated in distinct regions, while others were highly dispersed, e.g., C10-13, Fig. 4-II, versus C6 or C14, Fig. 4II. Similar to other studies (Raudsepp-Hearne et al. 2010), we highlight distinct spatial patterning in agriculture-dominated bundles (in our case in southern Sweden) and forest-dominated bundles (in our case mainly in northern Sweden). Likewise, diverse bundles can characterize urban-near landscapes (Queiroz et al. 2015), such as the region near Stockholm in our case, e.g., C6, $\mathrm{C} 8, \mathrm{C} 11, \mathrm{C} 12$, and C14, Fig. 4-II. Our results that include all game species suggest that hunting occurs throughout all landscapes, and that spatial structure rather emerges from the type of species harvested, as seen in previous research, e.g., deer (RaudseppHearne et al. 2010, Turner et al. 2014). Our clusters provide clear entry points for considering specific wildlife management goals in regionalized planning, for instance to avoid conflicts between ungulates and other land uses, e.g., browsing or crop damages (Dressel et al. 2018). Mapping such social-ecological interactions, as we do here, can help to identify potential conflict hotspots to adjust management across land uses and to agree on common goals to ensure multi-functionality (Dressel et al. 2018).
More dispersed bundles might be more challenging to address through policy making, but foster important opportunities for learning. For instance, regions in south-east and south-central Sweden might face similar challenges related to co-occurrence of agriculture, smaller deer species, and wild boar (C7 and C8, Fig. 5 -II), yet have low agreement on wildlife management goals (Dressel et al. 2018), and relevant authorities might not be aware of similarities across these regions. Likewise, ecologically more similar systems, e.g., northern Sweden (C3, C7, and C13, Fig. 4II) may suffer from problems to agree on goals as forest and mountainous landscapes may provide high diversity of services (Crouzat et al. 2015). Our clustering therefore not only provides a starting point for coordination across sectors, and possible selfreflection among landowners, but also encourages municipalities, which are geographically separate but share similar bundle characteristics, to foster exchange against the context of similar challenges that they face. Next to understanding functional similarities and differences to aid decision making, archetypical bundles also help to identify the drivers predicting service distribution and which models of human-nature interactions are most applicable for a given region and set of services (Meacham et al. 2016, Sietzet al. 2019). Finally, our bundles point to potential subsidiary effects in which municipalities in service-poor bundles might benefit or suffer from neighboring service-rich municipalities. As wildlife moves freely across anthropogenic landscapes, understanding such subsidy and neighborhood effects is important for planning and management to avoid unwanted or surprising outcomes.

Some of our bundles clearly point to regions where harvest, in particular of ungulates, was below-average in relation to other land uses. This finding is interesting as bundles in which intensive harvest, particularly of ungulates, co-occurred with agriculture and forestry may be interpreted as hunting having conflictmitigating potential, but may also indicate a functional response by hunters to the occurrence of wolves (Canis lupus; Wikenros et al. 2015). However, understanding the causality behind the associations we found was beyond the scope of our study. Still, we want to emphasize that spatial context is important here, as wildlife mobility and habitat use can distribute damages disproportionally (Kuijper et al. 2009, Fox and Madsen 2017). Given the risk of disservices produced by wildlife, and particularly ungulates (Beguin et al. 2016), it is important to develop common goals among different land-use sectors in order to avoid tradeoffs associated with a lack of wildlife control (through predators or hunting) in forage-rich landscapes (Sjolander-Lindqvis and Sandström 2019). Bundles with below-average harvest may indicate areas where potential disservices generated by wildlife are not balanced by services provided through hunting or, alternatively, there are no perceived disservices. Studying the causality behind this lack of spatial associations among hunting, agriculture, and forestry, respectively, would be a fruitful area for future research.

We used a comprehensive dataset on hunting, agriculture, and forestry to carry out the first identification of land-use bundles, including hunting of several functional wildlife groups. A few limitations need mentioning. First, some of our input data were not ideal. For instance, crop yields represent minimum values and likely underestimate total crop production because of how 
reporting in Sweden is carried out (only farmers with $>5$ ha cropland and $\geq 20$ farmers per crop are considered). Likewise, grassland yields were only available for grassland on arable land, but not for pastures. Second, following standard measures to compare among crop types, we treated all crops equally, i.e., using their estimated yield. Thus, we did not consider their caloric value, which may affect to some degree yield calculations. Third, the spatial resolution of some desirable indicators was too coarse to be included here, such as for pesticide or fertilizer use. Fourth, our analysis captures broad-scale patterns, which is interesting, but can mask more fine-scale patterns. We therefore advise caution in interpreting our results at a local scale. Fifth, interpretation should consider that the identification of our bundles is based on relative, and not absolute, comparison of indicator values, e.g., clear-cut area per municipality might be several standard deviations above the country average, but still small. Finally, our number of bundles depend on the parameterization and while we performed extensive analyses to identify the optimal cluster number, a different number of clusters would lead to different results.

\section{CONCLUSION}

Our findings suggest that hunting is a widespread but often overlooked land use. Throughout Europe, wildlife species are increasing in numbers and are rapidly expanding their range, thereby increasingly interacting with other land uses and producing services (restoring ecosystem functioning, hunting opportunities, game meat, wildlife viewing) and disservices (crop and browsing damages, vehicle collisions, diseases). This translates into an immediate need for more integrative, crosssectoral planning and policy making beyond jurisdictional borders, particularly considering that many land users engage in multiple land uses, including hunting. Three main considerations can be learned from our case study. First, including different functional wildlife groups emphasizes that hunting occurs throughout all landscapes available, making it a key land-use interest. Second, wildlife interact closely with different land-use activities, suggesting integrating wildlife management in land-use planning would be beneficial to avoid and mitigate conflicts, and to leverage synergies. Third, wildlife mobility results in nonuniform landscape utilization in response to resources provided by other land uses, and different wildlife groups are hunted for different reasons, e.g., meat, recreation, and population control, generating distinct social-ecological relationships between hunting and other land uses. Considering scale effects and spatiotemporal winner-loser constellations can help to prevent unwanted planning outcomes in such situations (Cord et al. 2017). Our approach identifies areas for context-specific policies to foster value-producing, sustainable hunting, agriculture, and forestry in multi-functional landscapes.

More generally, understanding the interactions between people and nature is at the heart of addressing major sustainability problems we face. A key challenge in this context is how to structure the diversity and complexity of such interactions, the social-ecological context in which they occur, and the services these interactions produce in a meaningful way (Levers et al. 2018, Schulp et al. 2019, Pacheco-Romero et al. 2020). Finding archetypical, recurring combinations of interaction has become a key tool to reach an intermediate level of abstraction between case specificity and general explanations (Cumming et al. 2014,
Oberlack et al. 2019). Here, we derive the first bundles for hunting of a broad range of game species in relation to other land uses, highlighting how archetype analyses can serve as a basis for contextualized, tailored planning, management, and policy making.

Responses to this article can be read online at: https://www.ecologyandsociety.org/issues/responses. $\mathrm{php} / 12882$

\section{Author Contributions:}

W. N., C.L., J. P. G. M. C., and T. K. designed the study. W. N. gathered the data. C. L. and W. N. conducted the analyses. F. W. gave advice on the analyses. $W . N$. and T. K. drafted the manuscript together with C. L., J. P. G. M. C., F. W., and N. J. S. All authors contributed to the text. All authors agree to be held accountable for the content therein and approve the final version of the manuscript.

\section{Acknowledgments:}

We are grateful for funding by the Swedish Environmental Protection Agency (research program "Beyond Moose - ecology and management of multispecies ungulate systems," NV-01337-15/ NV-03047-16/NV-08503-18). We thank the Swedish Association for Hunting and Wildlife Management for supplying us with data from Swedish Game Monitoring. The authors declare that they have no competing interests. T. K. is grateful to the Knut and Alice Wallenberg Foundation for funding a Wallenberg Professorship that has enabled this work. We thank S. Juthberg for help with language editing. We are grateful for the constructive and very helpful comments made by the two reviewers and the editors.

\section{Data Availability:}

The data is publicly available and can be downloaded via the following homepages: Harvest data - www.viltdata.se, www. algdata.se Cropdata - www.jordbruksverket.se, www.scb.se Forestry data - www.scb.se, www. skogsstyrelsen.se

\section{LITERATURE CITED}

Albert, C., C. Fürst, I. Ring, and C. Sandström. 2020. Research note: spatial planning in Europe and Central Asia - enhancing the consideration of biodiversity and ecosystem services. Landscape and Urban Planning 196:103741. https://doi. org/10.1016/j.landurbplan.2019.103741

Andersen, R., P. Duncan, and J. D. C. Linnell. 1998. The European roe deer: the biology of success. Journal of Wildlife Management 64(2):608-609. https://doi.org/10.2307/3803262

Angelstam, P., M. Manton, S. Pedersen, and M. Elbakidze. 2017. Disrupted trophic interactions affect recruitment of boreal deciduous and coniferous trees in northern Europe. Ecological Applications 27:1108-1123. https://doi.org/10.1002/eap.1506

Antonson, H., and U. Jansson. 2011. Agriculture and forestry in Sweden since 1900: geographical and historical studies. The Royal Swedish Academy of Agriculture and Forestry (KSLA), Stockholm, Sweden. 
Apollonio, M., R. Andersen, and R. Putman. 2010. European ungulates and their management in the 21 st century. Cambridge University Press, Cambridge, UK.

Beguin, J., J.-P. Tremblay, N. Thiffault, D. Pothier, and S. D. Côté. 2016. Management of forest regeneration in boreal and temperate deer-forest systems: challenges, guidelines, and research gaps. Ecosphere 7(10):e01488. https://doi.org/10.1002/ecs2.1488

Bjärstig, T., C. Sandström, S. Lindqvist, and E. Kvastegård. 2014. Partnerships implementing ecosystem-based moose management in Sweden. International Journal of Biodiversity Science, Ecosystem Services and Management 10:228-239. http://doi. org/10.1080/21513732.2014.936508

Bjärstig, T., C. Thellbro, O. Stjernström, J. Svensson, C. Sandström, P. Sandström, and A. Zachrisson. 2018. Between protocol and reality - Swedish municipal comprehensive planning. European Planning Studies 26:35-54. https://doi. org/10.1080/09654313.2017.1365819

Boman, M., L. Mattsson, G. Ericsson, and B. Kriström. 2011. Moose hunting values in Sweden now and two decades ago: the Swedish hunters revisited. Environmental and Resource Economics 50(4):515-530. https://doi.org/10.1007/s10640-011-9480$\underline{\mathrm{Z}}$

Chapron, G., P. Kaczensky, J. D. C Linnell, M. Von Arx, D. Huber, H. Andrén, J. V. López-Bao, M. Adamec, F. Álvares, O. Anders, et al. 2014. Recovery of large carnivores in Europe's modern human-dominated landscapes. Science 346(6216):1517-1519. https://doi.org/10.1126/science.1257553

Cord, A. F., B. Bartkowski, M. Beckmann, A. Dittrich, K. Hermans-Neumann, A. Kaim, N. Lienhopp, K. Locher-Krause, J. Priess, C. Schroter-Schlaack, N. Schwarz, R. Seppelt, M. Strauch, T. Vaclavik, and M. Volk. 2017. Towards systematic analyses of ecosystem service trade-offs and synergies: main concepts, methods, and the road ahead. Ecosystem Services 28:264-272. https://doi.org/10.1016/j.ecoser.2017.07.012

Crouzat, E., M. Mouchet, F. Turkelboom, C. Byczek, J. Meersmans, F. Berger, P. J. Verkerk, and S. Lavorel. 2015. Assessing bundles of ecosystem services from regional to landscape scale: insights from the French Alps. Journal of Applied Ecology 52:1145-1155. https://doi.org/10.1111/1365-2664.12502

Cumming, G. S., A. Buerkert, E. M. Hoffmann, E. Schlecht, S. von Cramon-Taubadel, and T. Tscharntke. 2014. Implications of agricultural transitions and urbanization for ecosystem services. Nature 515(7525):50-57. 10.1038/nature13945. https://doi. org/10.1038/nature13945

Dawe, K. L., E. M. Bayne, and S. Boutin. 2014. Influence of climate and human land use on the distribution of white-tailed deer (Odocoileus virginianus) in the western boreal forest. Canadian Journal of Zoology 92(4):353-363. 10.1139/ cjz-2013-0262 https://doi.org/10.1139/cjz-2013-0262

Dressel, S., G. Ericsson, and C. Sandström. 2018. Mapping socialecological systems to understand the challenges underlying wildlife management. Environmental Science \& Policy 84:105-112. https://doi.org/10.1016/j.envsci.2018.03.007
Deutscher Jagdverband. Zahlen und facten. Deutscher Jagdverband, Berlin, Germany. [online] URL: https://www. jagdverband.de/zahlen-und-fakten

Eurostat. Statistics explained - Glossary: livestock unit (LSU). Eurostat, European Commission, Luxembourg. [online] URL: http://ec.europa.eu/eurostat/statistics-explained/index.php/Glossary: Livestock unit (LSU)

Fischer, A., C. Sandström, M. Delibes-Mateos, B. Arroyo, D. Tadie, D. Randall, F. Hailu, A. Lowassa, M. Msuha, V. Kereži, S. Reljić, J. D. C. Linnell, and A. Majić. 2013. On the multifunctionality of hunting - an institutional analysis of eight cases from Europe and Africa. Journal of Environmental Planning and Management 56(4):531-552. https://doi. org/10.1080/09640568.2012.689615

Fox, A. D., and J. Madsen. 2017. Threatened species to superabundance: the unexpected international implications of successful goose conservation. Ambio 46:179-187. https://doi. org/10.1007/s13280-016-0878-2

Frei, B., D. Renard, M. G. E. Mitchell, V. Seufert, R. ChaplinKramer, J. M. Rhemtulla, and E. M. Bennet. 2018. Bright spots in agricultural landscapes: identifying areas exceeding expectations for multifunctionality and biodiversity. Journal of Applied Ecology 55:2731-2743. https://doi.org/10.1111/1365-2664.13191

Gordon, I. J., A. J. Hester, and M. Festa-Bianchet. 2004. The management of wild large herbivores to meet economic, conservation, and environmental objectives. Journal of Applied Ecology 41:1021-1031. https://doi.org/10.1111/j.0021-8901.2004.00985. $\underline{\mathrm{x}}$

Gren, I. M., T. Haggmark-Svensson, K. Elofsson, and M. Engelmann. 2018. Economics of wildlife management - an overview. European Journal of Wildlife Research 64:22. https:// doi.org/10.1007/s10344-018-1180-3

Harrison, A. L., N. Petkov, D. Mitev, G. Popgeorgiev, B. Gove, and G. M. Hilton. 2018. Scale-dependent habitat selection by wintering geese: implications for landscape management. Biodiversity and Conservation 27:167-188. https://doi.org/10.1007/ s10531-017-1427-4

Holting, L., S. Jacobs, M. R. Felipe-Lucia, J. Maes, A. V. Norstrom, T. Plieninger, and A. F. Cord. 2019. Measuring ecosystem multifunctionality across scales. Environmental Research Letters 14(12):124083. https://doi.org/10.1088/1748-9326/ $\underline{\mathrm{ab} 5 \mathrm{ccb}}$

Karrasch, L., T. Klenke, and M. Kleyer. 2019. Land-use elements and attributed ecosystem services: an archetype approach to landuse evaluation at the German North Sea coast. Ecology and Society 24(2):13. https://doi.org/10.5751/ES-10744-240213

Kohonen, T. 2001. Self-organizing maps. Third edition. Springer, Berlin, Germany. https://doi.org/10.1007/978-3-642-56927-2

Kuemmerle, T., C. Levers, K. Erb, S. Estel, M. R. Jepsen, D. Muller, C. Plutzar, J. Stürck, P. J. Verkerk, and P. H. Verburg. 2016. Hotspots of land use change in Europe. Environmental Research Letters 11(6):064020. https://doi.org/10.1088/1748-93$\underline{26 / 11 / 6 / 064020}$ 
Kuijper, D. P. J., J. P. G. M. Cromisgt, M. Churski, B. Adam, B. Jedrzejewska, and W. Jedrzejewska. 2009. Do ungulates preferentially feed in forest gaps in European temperate forest? Forest Ecology and Management 258:1528-1535. https://doi. org/10.1016/j.foreco.2009.07.010

Levers, C., D. Müller, K. Erb, H. Haberl, M. R. Jepsen, M. J. Metzger, P. Meyfroidt, T. Plieninger, C. Plutzar, J. Stürck, P. H. Verburg, P. J. Verkerk, and T. Kuemmerle. 2018. Archetypical patterns and trajectories of land systems in Europe. Regional Environmental Change 18:715-732. https://doi.org/10.1007/ s10113-015-0907-x

Linnell, J. D. C., B. Cretois, E. B. Nilsen, C. M. Rolandsen, E. J. Solberg, V. Veiberg, P. Kaczensky, B. Van Moorter, M. Panzacchi, G. R. Rauset, and B. Kaltenborn. 2020. The challenges and opportunities of coexisting with wild ungulates in the humandominated landscapes of Europe's anthropocene. Biological Conservation 244:108500. https://doi.org/10.1016/j.biocon.2020.108500

Ljung, P. E., S. J. Riley, T. A. Heberlein, and G. Ericsson. 2012. Eat prey and love: game-meat consumption and attitudes toward hunting. Wildlife Society Bulletin 36(4):669-675. https://doi. org $/ 10.1002 /$ wsb. 208

Massei, G., J. Kindberg, A. Licoppe, D. Gacic, N. Sprem, J. Kamler, E. Baubet, U. Hohmann, A. Monaco, J. Ozolins, et al. 2015. Wild boar populations up, numbers of hunters down? A review of trends and implications for Europe. Pest Management Science 71:492-500. https://doi.org/10.1002/ps.3965

Meacham, M., C. Queiroz, A. V. Norström, and G. D. Peterson. 2016. Social-ecological drivers of multiple ecosystem services: what variables explain patterns of ecosystem services across the Norrström drainage basin? Ecology and Society 21(1):14. http:// doi.org/10.5751/ES-08077-210114

Mensah, J. T., and K. Elofsson. 2017. An empirical analysis of hunting lease pricing and value of game in Sweden. Land Economics 93:292-308. https://doi.org/10.3368/le.93.2.292

Navarro, L., and H. Pereira. 2012. Rewilding abandoned landscapes in Europe. Ecosystems 15:900-912. https://doi. org/10.1007/s10021-012-9558-7

Oberlack, C., D. Sietz, E. B. Bonanomi, A. de Bremond, J. Dell'Angelo, K. Eisenack, E. C. Ellis, G. Epstein, M. Giger, A. Heinimann, C. Kimmich, M. T. J. Kok, D. Manuel-Navarrete, P. Messerli, P. Meyfroidt, T. Vaclavik, and S. Villamayor-Tomas. 2019. Archetype analysis in sustainability research: meanings, motivations, and evidence-based policy-making. Ecology and Society 24(2):26. https://doi.org/10.5751/ES-10747-240226

Oldfield, T. E. E., R. J. Smith, S. R. Harrop, and N. LeaderWilliams. 2003. Field sports and conservation in the United Kingdom. Nature 423:531-533. https://doi.org/10.1038/nature01678

Pacheco-Romero, M., D. Alcaraz-Segura, M. Vallejos, and J. Cabello. 2020. An expert-based reference list of variables for characterizing and monitoring social-ecological systems. Ecology and Society 25(3):1. https://doi.org/10.5751/ES-11676-250301

Prager, K., A. Lorenzo-Arribas, H. Bull, M. S. Kvernstuen, L. E. Loe, and A. Mysterud. 2018. Social constraints in cross-boundary collaborative deer management. Ecology and Society 23(4):29. https://doi.org/10.5751/ES-10549-230429

Queiroz, C., M. Meacham, K. Richter, A. V. Norström, E. Andersson, J. Norberg, and G. Peterson. 2015. Mapping bundles of ecosystem services reveals distinct types of multifunctionality within a Swedish landscape. Ambio 44(1):89-101. https://doi. org/10.1007/s13280-014-0601-0

Raudsepp-Hearne, C., G. D. Peterson, and E. M. Bennet. 2010. Ecosystem services bundles for analyzing tradeoffs in diverse landscapes. Proceedings of the National Academy of Sciences of the United States of America 107:5242-5247. https://doi. org/10.1073/pnas.0907284107

Renard, D., J. M. Rhemtulla, and E. M. Bennett. 2015. Historical dynamics in ecosystem service bundles. Proceedings of the National Academy of Sciences of the United States of America 112(43):13411-13416. https://doi.org/10.1073/pnas.1502565112

Requena-Mullor, J. M., C. Quintas-Soriano, J. Brandt, J. Cabello, and A. J. Castro. 2018. Modeling how land use legacy affects the provision of ecosystem services in Mediterranean southern Spain. Environmental Research Letters 13(11):114008. https://doi. org/10.1088/1748-9326/aae5e3

R Foundation. 2019. The R Project for Statistical Computing. R Foundation, Vienna, Austria. [online] URL: https://r-project.org

Ripley, B. 1996. Pattern recognition and neural networks. Cambridge University Press, Cambridge, UK. https://doi. org/10.1017/CBO9780511812651

Sayer, J., T. Sunderland, J. Ghazoul, J.-L. Pfund, D. Sheil, E. Meijaard, M. Venter, A. Klintuni Boedhihartono, M. Day, and C. Garcia. 2013. Ten principles for a landscape approach to reconciling agriculture, conservation, and other competing land uses. Proceedings of the National Academy of Sciences of the United States of America 110:8349-8356. https://doi.org/10.1073/ pnas. 1210595110

Schiermeier, Q. 2019. Eat less meat: UN climate-change panel tackles diets. Nature 572:291. https://doi.org/10.1038/d41586-019-02409-7

Schulp, C. J. E., C. Levers, T. Kuemmerle, K. F. Tieskens, and P. H. Verburg. 2019. Mapping and modelling past and future land use change in Europe's cultural landscapes. Land Use Policy 80:332-344. https://doi.org/10.1016/j.landusepol.2018.04.030

Sietz, D., U. Frey, M. Roggero, Y. Gong, N. Magliocca, R. Tan, P. Janssen, and T. Václavík. 2019. Archetype analysis in sustainability research: methodological portfolio and analytical frontiers. Ecology and Society 24(3):34. https://doi.org/10.5751/ ES-11103-240334

Simoncini, R., I. Ring, C. Sandström, C. Albert, U. Kasymov, and R. Arlettaz. 2019. Constraints and opportunities for mainstreaming biodiversity and ecosystem services in the EU's common agricultural policy: insights from the IPBES assessment for Europe and Central Asia. Land Use Policy 88:104099. https:// doi.org/10.1016/j.landusepol.2019.104099

Sjolander-Lindqvis, A., and C. Sandström. 2019. Shaking hands: balancing tensions in the Swedish forested landscape. 
Conservation and Society 17:319-330. https://doi.org/10.4103/cs. cs 18112

Spake, R., R. Lasseur, E. Crouzat, J. M. Bullock, S. Lavorel, K. E. Parks, M. Schaafsma, E. M. Bennett, J. Maes, M. Mulligan, M. Mouchet, G. D. Peterson, C. J. E. Schulp, W. Thuiller, M. G. Turner, P. H. Verburg, and F. Eigenbrod. 2017. Unpacking ecosystem service bundles: towards predictive mapping of synergies and trade-offs between ecosystem services. Global Environmental Change 47:37-50. http://doi.org/10.1016/j. gloenvcha.2017.08.004

Statistics Sweden. 2015. Data on percentage distribution of land use in 2015 in Sweden. Statistics Sweden, Solna and Örebro, Sweden. [online] URL: http://www.statistikdatabasen.scb.se/ pxweb/sv/ssd/START MI MI0803 MI0803A/MarkanvLan/

Statistics Sweden. 2018. Data on crop yield and acreage forest in Sweden. Statistics Sweden, Solna and Örebro, Sweden. [online] URL: http://www.statistikdatabasen.scb.se/pxweb/sv/ssd/ START JO JO0601/SkordarL2/

Statistics Sweden. 2019. Data on number and distribution of inhabitants in Sweden. Statistics Sweden, Solna and Örebro, Sweden. [online] URL: http://www.statistikdatabasen.scb.se/ pxweb/sv/ssd/START BE BE0101 BE0101A/BefolkningNy/

Stürck J., and P. H. Verburg. 2017. Multifunctionality at what scale? A landscape multifunctionality assessment for the European Union under conditions of land use change. Landscape Ecology 32:481-500. https://doi.org/10.1007/s10980-016-0459-6

Svensson, J., W. Neumann, A. Zachrisson, T. Bjärstig, and C. Thellbro. 2020. National land-use and landscape interests in alpine and boreal landscapes - aspects of conflict, integration and synergy in sustainable landscape approaches. Sustainability 12:5113. https://doi.org/10.3390/su12125113

Swedish Association for Hunting and Wildlife Management (SAHWM). 2018. Data on Swedish hunting bag statistics of all species except moose within the hunting parish. SAHWM, Nyköping, Sweden.

Swedish Board of Agriculture. 2018. Data on crop and pasture acreage and livestock. Swedish Board of Agriculture, Jönköping, Sweden. [online] URL: https://statistik.sjv.se/PXWeb/pxweb/sv/ Jordbruksverkets $\% 20$ statistikdatabas/Jordbruksverkets $\%$ 20statistikdatabas Arealer 3\%20\%C3\%84goslagsareal $\% 20$ riket $\%$ 201\%C3\%A4n \%20kommun/JO0106H01.px/?rxid=5adf4929$\underline{\mathrm{f} 548-4 \mathrm{f} 27-9 \mathrm{bc} 9-78 \mathrm{e} 127837625}$

Swedish Forest Agency. 2017. Data on acreage of clear-cut in a given year, provided as shapefile, and data on yield of forest in Sweden. Swedish Forest Agency, Sweden. [online] URL: http:// geodpags.skogsstyrelsen.se/geodataport/feeds/UtfordAvverk.xml

Swedish Forest Agency. 2018. Strukturstatistik - Statistik om skogsägande 2017. Skogsstyrelsen, Rapport 2018712. Swedish Forest Agency, Sweden. [online] URL: https://www.skogsstyrelsen. se/globalassets/om-oss/rapporter/rapporter-2018/rapport-2018-12strukturstatistik-statistik-om-skogsagande-2017.pdf
Tieskens, K. F., Schulp, C. J. E., Levers, C., Lieskovský, J., Kuemmerle, T., Plieninger, T., and Verburg, P. H. 2017. Characterizing European cultural landscapes: accounting for structure, management intensity and value of agricultural and forest landscapes. Land Use Policy 62:29-39. https://doi. org/10.1016/j.1andusepol.2016.12.001

Turner, K. G., M. V. Odgaard, P. K. Bocher, T. Dalgaard, and J. C. Svenning. 2014. Bundling ecosystem services in Denmark: trade-offs and synergies in a cultural landscape. Landscape and Urban Planning 125:89-104. https://doi.org/10.1016/j. landurbplan.2014.02.007

U.S. Fish and Wildlife Service. 2016. National Survey of Fishing, Hunting, and Wildlife-Associated Recreation. U.S. Department of the Interior, U.S. Fish and Wildlife Service, U.S. Department of Commerce, U.S. Census Bureau, Washington, D.C., USA. [online] URL: https://www.census.gov/content/dam/Census/ library/publications/2018/demo/fhw16-nat.pdf

Václavík, T., S. Lautenbach, T. Kuemmerle, and R. Seppelt. 2013. Mapping global land system archetypes. Global Environmental Change 23:1637-1647. http://doi.org/10.1016/j.gloenvcha.2013.09.004

Van der Zanden, E. H., C. Levers, P. H. Verburg, and T. Kuemmerle. 2016. Representing composition, spatial structure, and management intensity of European agricultural landscapes: a new typology. Landscape and Urban Planning 150:36-49. https://doi.org/10.1016/j.landurbplan.2016.02.005

Walesiak, M., and A. Dudek. 2014. clusterSim: searching for optimal clustering procedure for a data set. [online] URL: https:// rdrr.io/cran/clusterSim/

Wehrens, R., and L. Buydens. 2007. Self- and super-organizing maps in $\mathrm{r}$ : the kohonen package. Journal of Statistical Software 21:1-19. https://doi.org/10.18637/jss.v021.i05

Weisberg, P. J., and H. Bugmann. 2003. Forest dynamics and ungulate herbivory: from leaf to landscape. Forest Ecology and Management 181:1-12. https://doi.org/10.1016/S0378-1127(03) $\underline{00123-3}$

Widemo, F., B. Elmhagen, and N. Liljebäck. 2019. Viltets ekosystemtjänster - en kunskapssammanställning, Swedish Environmental Protection Agency Report 6889, Swedish Environmental Protection Agency, Stockholm, Sweden.

Wikenros, C., H. Sand, R. Bergström, O. Liberg, and G. Chapron. 2015. Response of moose hunters to predation following wolf return in Sweden. PLoS ONE 10(4): e0119957. https://doi. org/10.1371/journal.pone.0119957

Wiklund, E., and G. Malmfors. 2014. Viltkött som en resurs, Swedish Environmental Protection Agency Report 6635, Swedish Environmental Protection Agency, Stockholm, Sweden. 


\section{Supplementary Information}

Table A1.1. Source, spatial resolution and unit of the indicators on the extent and intensity of hunting, agriculture, and forestry.

\begin{tabular}{llll}
\hline Data & Spatial level & Unit & Source \\
\hline $\begin{array}{l}\text { Hunting } \\
\text { Moose }\end{array}$ & Moose Management Area & heads & $\begin{array}{l}\text { Swedish Association for Hunting and Wildlife Management } \\
\text { (www.jagareforbundet.se) }\end{array}$ \\
$\begin{array}{lll}\text { Bears } \\
\text { All other game }\end{array}$ & $\begin{array}{l}\text { Municipality } \\
\text { Hunting parish }\end{array}$ & $\begin{array}{l}\text { National Veterinary Institute (www.sva.se) } \\
\text { heads }\end{array}$ & $\begin{array}{l}\text { Swedish Association for Hunting and Wildlife Management } \\
\text { (www.jagareforbundet.se) }\end{array}$ \\
& &
\end{tabular}

Agriculture

Crop cover

Pasture cover

Grassland cover

Livestock

Crop yield

Grassland yield
Municipality

Municipality

Municipality

Municipality

County

County ha

ha

ha

heads

$\mathrm{kg}$ per ha

kg per ha
Swedish Board of Agriculture (www.jordbruksverket.se) Swedish Board of Agriculture (www.jordbruksverket.se) Swedish Board of Agriculture (www.jordbruksverket.se) Swedish Board of Agriculture (www.jordbruksverket.se) Statistic Sweden (www.scb.se)

Statistic Sweden (www.scb.se)

\section{Forestry}

Forest cover

Clear-cuts

Forest yield
Municipality

Municipality

County ha

ha

$1000 \mathrm{~m}^{3}$
Swedish Board of Agriculture (www.jordbruksverket.se)

Swedish Forest Agency (www.skogsstyrelsen.se)

Swedish Forest Agency (www.skogsstyrelsen.se) 
Table A1.2. The functional groups and Latin names of the 63 wildlife species that we considered for the hunting land use, and the classification in the eight groups of game.

\section{Agriculture Birds}

Columba livia

Columba palumbus

Perdix perdix

Phasianus colchicus

\section{Bears}

Ursus arctos

Forest Grouse

Lagopus lagopus

Lagopus muta

Lyrurus tetrix

Tetrao urogallus

Tetrastes bonasia

\section{Hares}

Lepus europaeus

Lepus timidus

Oryctolagus cuniculus

\section{Meso-predators}

Chroicocephalus ridibundus

Corvus corax

Corvus cornix

Corvus frugilegus

Corvus monedula

Garrulus glandarius

Larus argentatus

Larus canus

Larus fuscus

Larus marinus

Martes martes

Meles meles

Mustela erminea

Mustela nivalis

Mustela putorius

Mustela putorius furo

Neovison vison

Nyctereutes procyonoides

Pica pica 
Procyon lotor

Sciurus vulgaris

Vulpus vulpus

\section{Ungulates}

Alces alces

Capreolus capreolus

Cervus elaphus

Dama dama

Sus scrofa

\section{Aquatic Mammals}

Castor fiber, Castor canadensis

Myocastor coypus

Ondatra zibethicus

\section{Waterfowl}

Anas acuta

Anas crecca

Anas platyrhynchos

Anser albifrons

Anser anser

Anser fabalis

Aythya ferina

Aythya fuligula

Branta canadensis

Bucephala clangula

Clangula hyemalis

Fulica atra

Mareca penelope

Melanitta fusca

Melanitta nigra

Mergus merganser

Mergus serrator

Phalacrocorax carbo

Somateria mollissima

Spatula clypeata 
Table A1.3. Crop types that we considered for arable (i.e. crop) and pasture land use.

\section{Crops}

Barley (inclusive winter and spring barley)

Brown beans

Corn

Linseed

Mixed grain and rye wheat

Mixed seed /cereal

Oats

Peas (cooking, fodder, vetch, field, and canned)

Potatoes for food and starch

Rape (inclusive winter and spring rape)

Rye (inclusive winter and spring rye)

Rye wheat/Triticale (inclusive winter and spring rye wheat/triticale)

Sugar beet

Turnip (inclusive winter and spring)

Wheat (inclusive winter and spring wheat)

Other unused arable land

Unspecified arable land

\section{Grassland}

Energy forest

Grazing mounds that is utilized

Green fodder

Mowing grounds used

Mowing meadows and green fodder

Mowing and grazing mounds used

Seed for seed harvest

Unused mowing and grazing meadows

\section{Other}

Garden plants

Other types of plants

Lay-land 
Figure A1.1. Sum of number harvested game in eight functional groups per municipality in Sweden, 2008-2016. Municipalities with zero animals harvested in white. Wildlife units (WU) using moose as reference unit (i.e., moose $=1.0$, roe deer $=0.15$, red deer $=0.56$, fallow $=0.29$, wild boar = 0.56; Wiklund and Malmfors 2014).
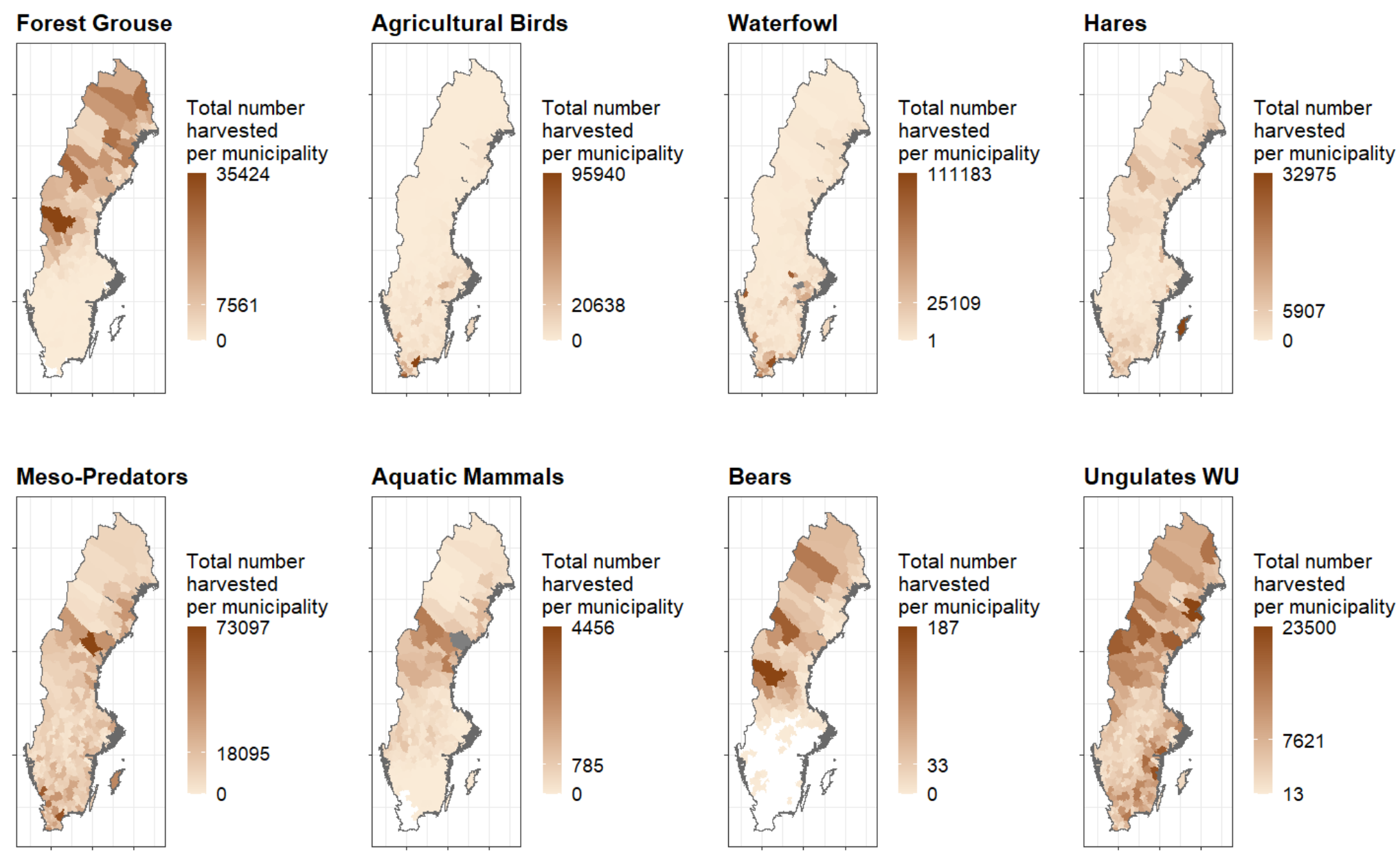
Figure A1.2. Sum of number harvested moose, roe deer, red deer, fallow deer, and wild boar (wildlife units) per municipality in Sweden, 20082016. Municipalities with zero animals harvested in white. Wildlife units (WU) using moose as reference unit (i.e., moose $=1.0$, roe deer $=0.15$, red deer $=0.56$, fallow $=0.29$, wild boar $=0.56$; Wiklund and Malmfors 2014)

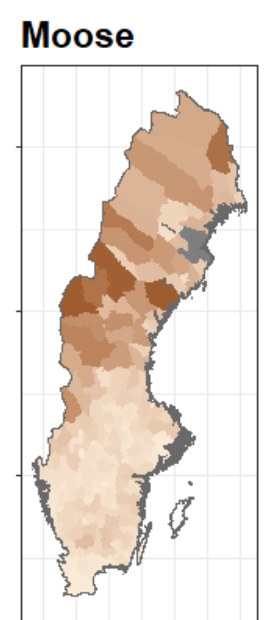

Total number harvested per municipality 22728

6322

0

\section{Fallow deer WU}

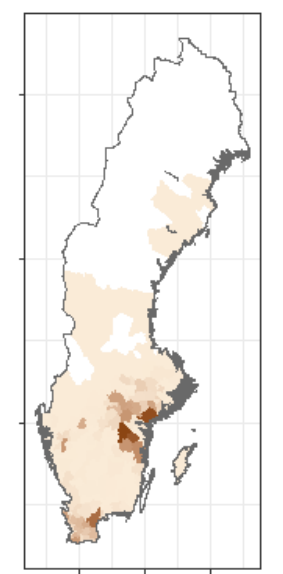

Total number harvested per municipality 4825

956

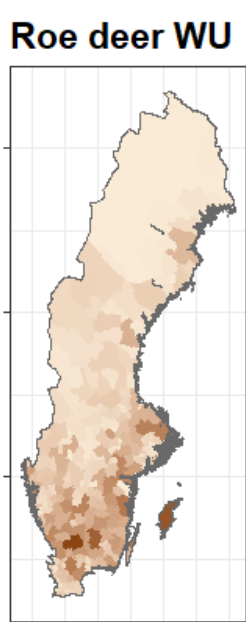

Total number harvested per municipality

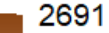

707

0

\section{Wild boar WU}

\section{Total number} harvested

per municipality

9874

2699

\section{Red deer WU}

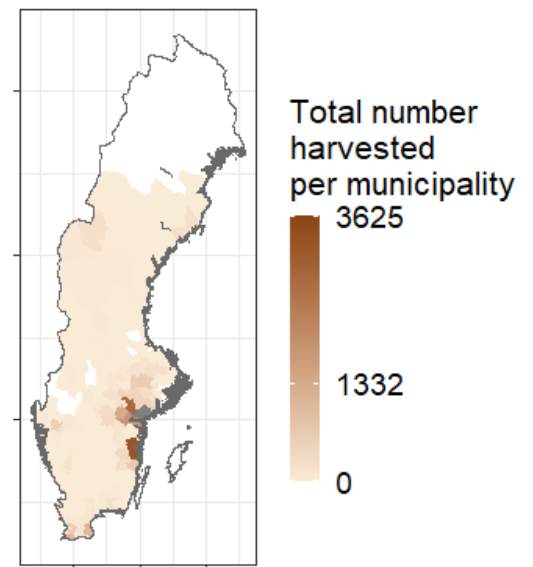


Figure A1.3. Performance plots that indicate the given optimal cluster number using the natural breakpoint in the mean Euclidean distance of the samples to their cluster centroid (blue line) and the Davies-Bouldin cluster index (red line), which relates intra- to inter-cluster variability. (A) Harvest of eight functional wildlife groups in relation to agriculture and forestry, (B) Ungulate harvest in relation to agriculture and forestry.

A

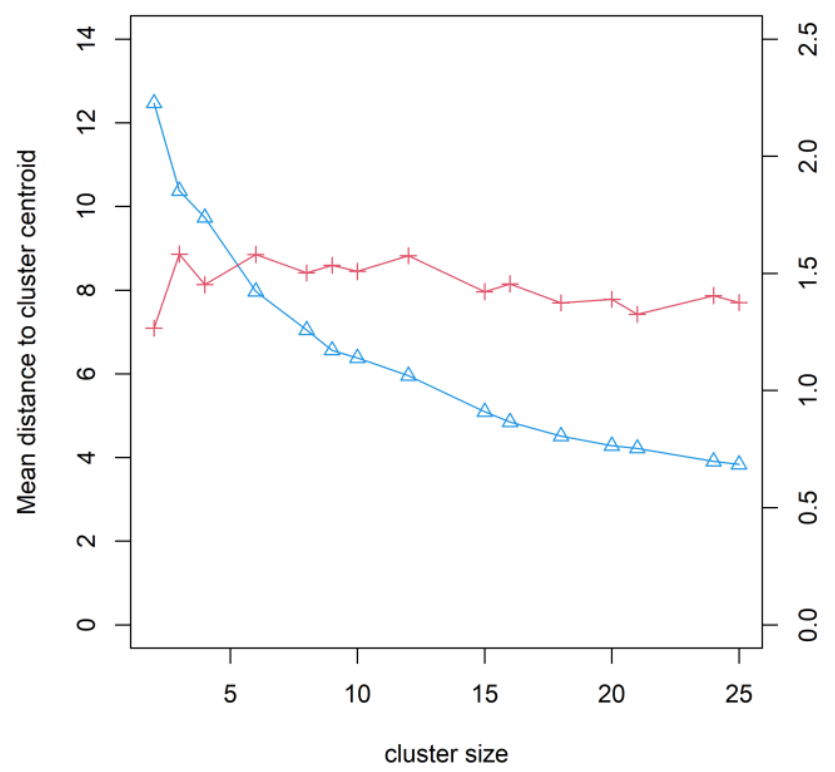

$\mathrm{B}$

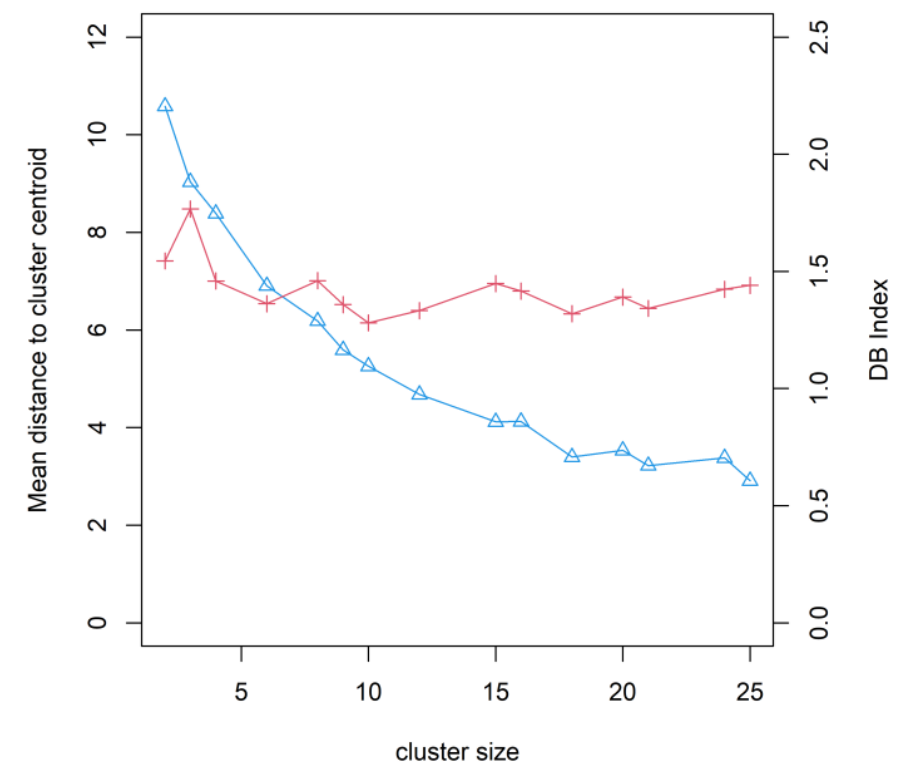

